\title{
Hubungan Koordinasi Mata kaki, Daya Ledak Otot Tungkai dan Percaya Diri dengan Hasil Lari Sprint 100 Meter pada Atlet PPLP Bangka Belitung
}

\author{
Topan Anggara ${ }^{1}$ \\ ${ }^{1}$ PPLP Bangka Belitung \\ *Corresponding Author. Email: topanpenjas@yahoo.co.id
}

\begin{abstract}
Abstrak : Penelitian korelasi ini bertujuan untuk memperoleh informasi tentang, ada tidaknya hubungan antara Koordinasi mata kaki, daya ledak otot tungkai, dan percaya diri dengan hasil lari sprint 100 meter pada atlet PPLP Bangka Belitung. Penelitian ini menggunakan pendekatan kuantitatif, metode survei. Subjek dalam penelitian ini adalah klub PPLP Bangka Belitung sebanyak 30 Orang. Pengambilan sampel dilakukan dengan menggunakan teknik Total Sampling. Berdasarkan Uji hipotesis, penelitian ini menyimpulkan terdapat hubungan antara koordinasi mata kaki dengan hasil lari sprint 100 meter pada atlet PPLP Bangka Belitung sebesar 0,939. Terdapat hubungan antara daya ledak otot tungkai dengan hasil lari sprint 100 meter pada atlet PPLP Bangka Belitung sebesar 0,937. Terdapat hubungan antara percaya diri dengan hasil lari sprint 100 meter pada atlet PPLP Bangka Belitung sebesar 0,981. Pengujian hipotesis yang terakhir terdapat hubungan antara koordinasi mata kaki, daya ledak otot tungkai dan percaya diri secara bersama-sama dengan hasil lari sprint 100 meter pada atlet PPLP Bangka Belitung sebesar 0,991 .
\end{abstract}

Kata Kunci : koordinasi mata kaki, daya ledak otot tungkai, percaya diri, Sprint 100 Meter

Abstract : Correlatian study aims to obtain information about the relationship of Coordination Foot eye, leg muscle Explosive power and self confidence with Results Sprint Run 100 Meters on Athletes PPLP Bangka Belitung as many as 30 people.The sample taken by using total sampling technique. Based on the hyphotesist, the researcher concluded that there is relationship between Coordination Foot eye and Results Sprint Run 100 Meters on Athletes PPLP Bangka Belitung by 0,939. There are relationship between leg muscle eksplosive power with Smash Results Sprint Run 100 Meters on Athletes PPLP Bangka Belitung by 0,937.There are relationship between confidence and Results Sprint Run 100 Meters on Athletes PPLP Bangka Belitung by 0,981.Testing the hypothesis that there is a relationship between Coordination Foot eye, leg muscle explosive power and self confidence with Results Sprint Run 100 Meters on Athletes PPLP Bangka Belitung by 0,991 .

Keyword : Coordination Foot eye, leg muscle Explosive power, self confidence, Results Sprint Run 100 Meters 
PENDAHULUAN

Atletik merupakan salah satu cabang olahraga yang tertua dari cabang-cabang olahraga lainnya. Karenanya atletik sering disebut sebagai induk dari cabang olahraga. Di mana gerakan-gerakan yang terdapat dalam cabang olahraga atletik itu adalah seperti: berjalan, berlari, melompat, dan melempar. Hal itu terdapat dalam kehidupan sehari-hari yang merupakan aktivitas dalam kehidupannya, bahkan hal itu telah dilakukan oleh manusia sejak jaman purba dalam upaya mempertahankan hidup, seperti dalam hal mencari nafkah dan melawan keadaan alam.

Hal ini tepatlah bila olahraga atletik ini pengembangannya harus dibina sedini mungkin. Kesempatan untuk itu banyak sekali apabila dilaksanakan melalui Pembinaan Koni dan sekolahsekolah terutama pada sekolah dasar dan menengah. Karena perkembangan prestasi dalam cabang atletik merupakan hal yang sangat penting demi kemajuan atau peningkatan prestasi olahraga dan bangsa Indonesia.
Berdasarkan hasil observasi peneliti pada Atlet Atletik PPLP Provinsi Bangka Belitung, terlihat beberapa masalah. Permasalahan yang didapatkan Peneliti Sebagai Berikut : Saat melakukan start blok, masih banyak kaki Yang menempel ke karpet, serta ragu -ragu Saat keluar dari start blok. Hal ini dikarenakan tidak terlatihnya kondisi fisik, Seperti Koordinasi Mata kaki, Daya ledak otot Tungkai, dan Percaya diri dalam menempuh jarak lari 100 Meter.

dan masih banyak pada saat lari Kecepatan maksimal duduk Tung-kai nya, dan tidak lurus yang harus nya di Lakukan.

Berdasarkan dari uraian di atas penulis tertarik mengadakan pene-litian tentang "Hubungan Koordin-asi mata kaki dan daya ledak otot tungkai, dan percaya diri dengan Hasil lari Sprint 100 Meter pada Atlet PPLP Bangka Belitung”.

Lari adalah lompatan yang ber-turutturut yang didalamnya terda-pat suatu fase dimana kedua kaki tidak menginjak pada tanah. Gerak lari secara keseluruhan di mulai dari saat kaki 
mulai menyentuk tanah sampai kemudian menyen-tuh tanah lagi. Yang dinilai dalam lari adalah kecepatan, menurut Tangkudung (2006:67) Kecepatan adalah kemampuan untuk berjalan berlari dan bergerak dengan sangat cepat. Pengembangan kecepatan berarti juga meliputi pengemba-ngan skil, sehingga teknik itu dila-kukan dengan kecepatan tinggi. Kecepatan adalah kemampuan otot atau sekelompok otot untuk menjawab rangsangan dalam wak-tu secepat (sesingkat) mungkin, kecepatan sebagai hasil perpadu-an dari panjang ayunan dan jumlah langkah. Sedangkan menurut Sukadiyanto dam Muluk (2011:116) menjelelaskan Kecepatan adalah kemampuan untuk menempuh jarak dengan cepat. Kemampuan untuk bergerak cepat dalam garis lurus merupakan komponen yang tidak terpisahkan dari sukses di berbagai olahraga. Garis lurus berlari dapat dibagi menjadi tiga tahap : akselerasi, pencapaian kecepatan maksimal pemeliharaan kecepatan maksimal.

\section{Teknik Lari Sprint}

IAAF (2001:6) menyatakan bahwa suatu start dalam teknik lari sprint yang baik ditandai dengan sifatsifat berikut Posisi aba-aba "ber-sedia"; Kaki yang paling cepat/ tangkas ditempatkan pada per-mukaan sisi miring block yang paling depan. Kedua jari- jari tangan diletakkan dibelakang garis start dan menopang badan dan kaki belakang ditempatkan pada block belakang, kepala rileks.

Tujuan melakukan fase topang yaitu untuk memperkecil saat sentuh dengan tanah dan untuk memaksimalkan dorongan ke depan.

Tujuan dari melakukan fase melayang yaitu untuk memaksimalkan dorongan kedepan dan untuk mempersiapkan suatu penempatan kaki yang efektif saat sentuh tanah.

Start yang baik memiliki beberapa karakteristik: 1. Memiliki konsentrasi penuh, tidak memikirkan hal lain di saat aba aba "bersedia" 2 . Mene-mpatkan keadaan diri dalam aba aba "siap" 3. Kedua kaki melakukan gerakan eksplosif pada blokdi sudut yang optimal pada start. Tiga variasi dalam start jongkok yang biasa 
digunakan pada garisstart 1. The Bunch start $(14-28 \mathrm{~cm}) 2$. The Medium start $(35-42 \mathrm{~cm})$ 3. The Elongated (50-70 $\mathrm{cm})$.

\section{Koordinasi Mata kaki}

Kemampuan koordinasi yang dimiliki seorang pelari sangat berarti dalam melakukan lari cepat dan kuat dari start sampai memasuki garis finish. Teknik gerakan lari haruslah memiliki keharmonisan gerak otot tungkai atas dan bawah, koordinasi tersebut merupakan Koordinasi Mata kaki. Menurut Sukadiyanto, Koordinasi merupakan hasil per-paduan kinerja dari kualitas otot, tulang, dan persendian dalam me-lakukan suatu gerak yang efektif dan efisien. Dimana komponen gerak yang terdiri dari energi, kontraksi otot, syaraf, tulang dan persendian merupakan koordinasi neuromuskuler. Koordinasi neuromuskuler adalah setiap gerak yang terjadi dalam urutan dan waktu yang tepat serta gerakannya mengandung tenaga. Sebab ter-jadinya gerak ditimbulkan oleh kontraksi otot, dan otot berkon-traksi karena adanya perintah yang diterima melalui sistem syaraf. Sedangkan menurut Taylor (2005:4) "Coordination. This is the state of integration of all the other cpmponents into a single function package so that grace, economy of movement, and physical efficiency are achieved at a high level". Selanjutnya menurut Ratamess (2012:13) menjelaskan "Gross motor coordination refers to the ability of an individual to perform a motor skill with good technique, rhythm, and accuracy". Sedangkan menurut Tangkudung (2012:72) "koordinasi adalah kemampuan untuk melakukan gerakan dengan berbagai tingkat kesukaran dengan cepat dan efisien dan penuh ketepatan".

Dari pendapat tersebut disimpulkan Koordinasi adalah kemampuan tubuh untuk melakukan berbagai macam gerakan dalam satu pola gerakan secara sistematis dan kontinu atau hal yang menyakan hubungan harmonis dari berbagai faktor yang terjadi pada suatu gerakan. Dengan memiliki tingkat koordinasi yang baik, gerakan yang dilakukan hanya membutuhkan energi 
sedikit, sehingga ada efesiensi gerak dan energi. Koordinasi yang rendah akan mengebabkan terjadinya cedera, terlebih lagi pada cabang-cabang olahraga yang membutuhkan keterampilan gerak yang kompleks dan halus.

Menurut Bompa dalam Sukadiyanto (2009:40) menyatakan, “pada dasarnya koordinasi dibedakan menjadi dua macam, yaitu koordinasi umum dan koordinasi khusus". Menurut Sage dalam Sukadiyanto (2009:66) menyatakan bahwa, "koordinasi umum merupakan kemampuang seluruh tubuh dalam menyesuaikan dan mengatur gerakan secara simultan pada saat melakukan suatu gerak". Artinya, bahwa setiap gerakan yang dilakukan melibatkan semua atau sebagian otototot, sistem syaraf, dan persendian. Pada umumnya setiap teknik dalam cabang olahraga merupakan dari perpaduan antara pandangan mata-tangan (hand eye-coordination) dan kerja kaki (footwork).

\section{Daya Ledak Otot Tungkai}

Salah satu unsur kondisi fisik yang memiliki peranan penting dalam kegiatan olahraga, baik sebagai unsur pendukung dalam suatu gerak tertentu maupun unsur utama dalam upaya pencapaian teknik gerak yang sempurna adalah daya ledak. Daya ledak tungkai sangat dibutuhkan dalam berbagai cabang olahraga, apalagi cabang olahraga yang menuntut aktifitas yang berat dan cepat seperti lari jarak pendek atau kegiatan yang harus dilakukan dalam waktu sesingkat mungkin dengan beban yang berat. Untuk mampu melaksanakan aktifitas, penggabungan antara kekuatan dan kecepatan pada otot tungkai yang dikerahkan secara bersama-sama dalam mengatasi tahanan beban dalam waktu yan relatif singkat. Menurut Sukadiyanto (2009:73) menjelaskn "Daya ledak merupakan terjemah dari kata explosive power atau power (bahasa inggris) dan schnelkraft (bahasa jerman). Berdasarkan kamus pengetahuan olahraga Jerman, schnelkraft $=$ power yang berarti kemampuan untuk meraih suatu kekuatan setinggi mungkin dalam 
waktu yang singkat”. Selanjutnya menurut Irawadi (2011:96) "Daya ledak otot tungkai sebagai kemampuan seseorang untuk menggerakkan tubuh atau bagian bagiannya secara kuat dan kecepatan tinggi”.

\section{Percaya Diri}

Kepercayaan diri meru-pakan suatu keyakinan dan sikap seseorang terhadap kemampuan pada dirinya sendiri dengan me-nerima secara apa adanya baik positif maupun negatif yang dibentuk dan dipelajari melalui proses belajar dengan tujuan untuk kebahagian dirinya.

Percaya diri atau "self confident" merupakan modal utama seorang atlet untuk dapat maju karena pencapaian prestasi yang tinggi dan pemecahan rekor atlet itu sendiri harus dimulai dengan percaya bahwa dia dapat dan sanggup melampaui prestasi yang pernah dicapainya, Sudibyo setyobroto Pribadi yang percaya diri selalu mengusahakan dirinya berfikir positif sebagai bentuk pengko-kohan percaya dirinya tersebut. Pola pikir yang negatif secara tidak langsung akan menjerumuskan pada kegagalan dan kekalahan, sehingga percaya diri-nya terkikis berfikir positif dari hal-hal yang paling kecil dan sangat mendasar agar benarbenar bisa berfikir positif seutuhnya. Orang yang mempunyai percaya diri biasanya hidupnya menye-nangkan dan lebih tentram.

Berdasarkan model sport confidence yang dikembang-kannya, Vealey dan Knight (2008) "mengidentifikasi 3 kom-ponen atau dimensi dalam sportconfidence, yaitu : 1. Latihan dan ketrampilan fisik (Physical skills and Training) 2. Efisiensi Kognitif (Cognitive Efficiency) 3. Keuletan (Resilience).

Weinberg dan Gould (dalam Satiadarma, 2000) menyatakan bahwa rasa kepercayaan diri atlet (sportconfidence) memberi dampak posisitif dalam hal-hal berikut : 1. Emosi 2. Konsentrasi 3. Sasaran 4. Usaha 5. Strategi 6. Momentum. Dengan memiliki sport-confidnce yang tinggi, individu akan lebih memiliki kesempatan untuk memperoleh momentum (saat yang tepat) untuk bertindak. Tanpa sport-confidence yang tinggi, usaha individu menjadi terbatas 
dan peluang yang dikembangkannya juga menjadi terbatas, sehingga momentum untuk bertindak menjadi terbatas pula. Dalam olahraga Atletik Banyak Faktor Yang Harus dirubah Agar Mencapai Perpormance yang diinginkan, seorang atlit bukan hanya memerlukan kemampuan fisik yang baik akan tetapi seorang atlit harus memiliki unsur-unsur lain untuk mencapai prestasi salah satu nya dibidang psikologi yaitu percaya diri. Salah satu modal utama dan syarat mutlak untuk mencapai prestasi olahraga yang gemilang adalah memiliki percaya diri (self confidence atau confidence in oneself). Hornby menyatakan dalam Husdarta, "Over confidence atau percaya diri yang berlebihan dapat berakibat kurang menguntungkan terhadap atlet karena dengan tumbuhnya over confidence muncul pula rasa dan pikir "menganggap enteng" lawan. Disisi lain over confidence dapat menyebabkan seorang siswa/atlet mudah mengalami frustasi jika ia dikalahkan lawannya". Sedang kan Saranson dalam Komarudin (2013:69) menjelaskan bahwa "kepercayaan diri adalah perasaan yang berisi keku-atan, kemampuan dan kemampuan untuk melakukan dan meng-hasilkan sesuatu yang dilandasi keyakinan untuk sukses".

Lauser dalam Nur Ghuron mendefinisikan (2010:34) "kepercayaan diri diperoleh dari pengalaman hidup. Kepercayaan diri merupakan salah satu aspek kepribadian yang berupa keyakinan akan kemampuan diri seseorang sehingga tidak terpengaruh oleh orang lain dan dapat bertindak sesuai kehendak, gembira, optimis, cukup toleran dan bertanggung jawab". Dari penjelasan tersebut disimpulkan kepercayaan diri adalah perasaan yang berisi kekuatan, kemampuan dan kemampuan untuk melakukan dan menghasilkan sesuatu yang dilandasi keyakinan dan sukses.

\section{METODE PENELITIAN}

Metode penelitian yang digunakan dalam penelitian ini adalah pendekatan kuantitatif, metode su-rvei dengan teknik pengukuran dan tes. 
Sedangkan teknik analisis Variabel endogen terdiri dari hasil lari menggunakan pendekatan kore-lasi. $\quad$ sprint 100 meter (Y).

Arikunto (2013 : 313) menya-takan "Penelitian korelasi bertujuan untuk menemukan ada tidaknya hubungan dan apabila ada, berapa eratnya hubungan serta berarti atau tidak hubungan itu".

Jadi, penelitian korelasi

\section{HASIL DAN PEMBAHASAAN}

Koordinasi Mata Kaki terhadap

Hasil Lari Sprint 100 Meter

Hasil perhitungan dan pengujian uji

ANNOVA dengan SPSS

koordinasi mata kaki berpengaruh langsung positif terhadap hasil lari sprint 100 meter. Sebagaimana disajikan dalam tabel 1.

bebas (eksogen) dengan variabel terikat (endo-gen).1 Variabel yang dikaji terdiri dari empat variabel yang terdiri dari tiga variabel eksogen (bebas) dan satu variabel endogen (terikat). Variabel eksogen terdiri dari koordinasi mata kaki (X1), daya ledak otot tungkai (X2) dan rasa percaya diri (X3).

Tabel 1. ANNOVA Koordinasi Mata Kaki terhadap Hasil Lari Sprint 100 Meter

\begin{tabular}{llrrrrr}
\hline & & \multicolumn{1}{c}{ Sum of } & \multicolumn{2}{c}{ Mean } & & \multicolumn{1}{c}{ S } \\
& Model & \multicolumn{1}{c}{ Squares } & Df & \multicolumn{1}{c}{ Square } & \multicolumn{1}{c}{ F } \\
\hline Regression & 6928,681 & 1 & 6928,681 & 428,848 &, $000^{\mathrm{b}}$ \\
1 Residual & 452,382 & 28 & 16,156 & & \\
& Total & 7381,062 & 29 & & & \\
\hline
\end{tabular}

Dari pencarian diatas maka diketahui $\mathrm{F}_{\text {hitung }}$ sebesar 428,848 sedangkan $\mathrm{n}-2$
$F_{\text {tabel }}$ sebesar 4,20. Kriteria pengujian :

Terima $\mathrm{H}_{0}$ jika $\mathrm{F}_{\text {hitung }}<\mathrm{F}_{\text {tabel }}$, Tolak $\mathrm{H}_{0}$ 
jika $F_{\text {hitung }}>F_{\text {tabel }}$, dari data tersebut diperoleh $F_{\text {hitung }}>F_{\text {tabel }}$ yaitu 428,848 > 4,20 maka $\mathrm{H}_{0}$ ditolak, artinya model regresi sangat signifikan

Daya Ledak Otot Tungkai terhadap Hasil Lari Sprint 100 Meter.
Hasil perhitungan dan pengujian uji ANNOVA dengan SPSS

Daya ledak otot tungkai berpengaruh langsung positif terhadap hasil lari sprint 100 meter. Sebagaimana disajikan dalam tabel 2.

Tabel 2. ANNOVA Keberartian Daya Ledak Otot Tungkai terhadap Hasil Lari Sprint

\begin{tabular}{|c|c|c|c|c|c|}
\hline \multicolumn{6}{|c|}{100 Meter } \\
\hline Model & $\begin{array}{l}\text { Sum of } \\
\text { Squares }\end{array}$ & df & $\begin{array}{l}\text { Mean } \\
\text { Square }\end{array}$ & $\mathrm{F}$ & Sig. \\
\hline Regression & 6917,781 & 1 & 6917,781 & 419,497 &, $000^{b}$ \\
\hline 1 Residual & 461,739 & 28 & 16,491 & & \\
\hline Total & 7379,520 & 29 & & & \\
\hline
\end{tabular}

Dari pencarian diatas maka diketahui $F_{\text {hitung }}$ sebesar 419,497 sedangkan $n-2$ $F_{\text {tabel }}$ sebesar 4,20. Kriteria pengujian : Terima $\mathrm{H}_{0}$ jika $\mathrm{F}_{\text {hitung }}<\mathrm{F}_{\text {tabel }}$, Tolak $\mathrm{H}_{0}$ jika $F_{\text {hitung }}>F_{\text {tabel. }}$ dari table tersenut dapat disimpulkan $\mathrm{F}_{\text {hitung }}>\mathrm{F}_{\text {tabel }}$ yaitu 419,497 > 4,20 maka $\mathrm{H}_{0}$ ditolak, artinya model regresi sangat signifikan.

\section{Percaya Diri terhadap Hasil Lari Sprint 100 Meter}

Hasil perhitungan dan pengujian uji ANNOVA dengan SPSS Daya ledak otot tungkai berpengaruh langsung positif terhadap hasil lari sprint 100 meter. Sebagaimana disajikan dalam tabel 3.

Tabel 3. ANNOVA Percaya Diri terhadap Hasil Lari Sprint 100 Meter

\begin{tabular}{|c|c|c|c|c|c|c|c|}
\hline \multicolumn{2}{|c|}{ Model } & $\begin{array}{l}\text { Sum of } \\
\text { Squares }\end{array}$ & $\mathrm{df}$ & & $\begin{array}{l}\text { Mean } \\
\text { Square }\end{array}$ & $\mathrm{F}$ & Sig. \\
\hline \multirow{3}{*}{1} & Regression & 7243,140 & & 1 & 7243,140 & 1470,446 &, $000^{\mathrm{b}}$ \\
\hline & Residual & 137,923 & & 28 & 4,926 & & \\
\hline & Total & 7381,062 & & 29 & & & \\
\hline
\end{tabular}


Dari pencarian diatas maka diketahui $\mathrm{F}_{\text {hitung }}$ sebesar 1470,446 sedangkan n $2 \mathrm{~F}_{\text {tabel }}$ sebesar 4,20.Kriteria pengujian : Terima $\mathrm{H}_{0}$ jika $\mathrm{F}_{\text {hitung }}<\mathrm{F}_{\text {tabel }}$, Tolak $\mathrm{H}_{0}$ jika $F_{\text {hitung }}>F_{\text {tabel }}$. Dari hasil tersebut dapat di simpulkan $\mathrm{F}_{\text {hitung }}>\mathrm{F}_{\text {tabel }}$ yaitu 1470,446>4,20 maka $\mathrm{H}_{0}$ ditolak, artinya model regresi sangat signifikan. terhadap Hasil Lari Sprint 100 Meter

Hasil perhitungan dan pengujian uji ANNOVA dengan SPSS Koordinasi mata kaki, daya ledak otot tungkai dan percaya diri berpengaruh langsung positif terhadap hasil lari sprint 100 meter. Sebagaimana disajikan dalam tabel 4.

\section{Koordinasi Mata Kaki, Daya Ledak}

\section{Otot Tungkai dan Percaya Diri}

Tabel 4. Keberartian Regresi Ganda

\begin{tabular}{|c|c|c|c|c|c|c|c|}
\hline \multicolumn{2}{|c|}{ Model } & $\begin{array}{l}\text { Sum of } \\
\text { Squares }\end{array}$ & df & & $\begin{array}{l}\text { Mean } \\
\text { Square }\end{array}$ & $\mathrm{F}$ & Sig. \\
\hline \multirow{3}{*}{1} & Regression & 7314,958 & & 3 & 2438,319 & 981,947 &, $000^{\mathrm{b}}$ \\
\hline & Residual & 64,562 & & 26 & 2,483 & & \\
\hline & Total & 7379,520 & & 29 & & & \\
\hline
\end{tabular}

Dari pencarian diatas maka diketahui $\mathrm{F}_{\text {hitung }}$ sebesar 981,947, sedangkan $\mathrm{n}-$ $3 \mathrm{~F}_{\text {tabel }}$ sebesar 4,21. Kriteria pengujian : Terima $\mathrm{H}_{0}$ jika $\mathrm{F}_{\text {hitung }}<\mathrm{F}_{\text {tabel }}$, Tolak $\mathrm{H}_{0}$ jika $F_{\text {hitung }}>F_{\text {tabel }}$ Jadi dari hasil perhitungan tersebut di simpulkan $\mathrm{F}_{\text {hitung }}>\mathrm{F}_{\text {tabel }}$ yaitu 981,947> 4,21 maka $\mathrm{H}_{0}$ ditolak, artinya model regresi $\hat{\mathrm{Y}}=$ $171,898+2,001 X_{1}+9,379 X_{2}+$ $1,266 \mathrm{X}_{3}$ sangat signifikan.

KESIMPULAN
Terdapat hubungan yang positif antara Koordinasi Mata Kaki $\left(\mathrm{X}_{1}\right)$ dengan Hasil Lari Sprint 100 Meter (Y). Hal ini berarti makin baik Koordinasi Mata Kaki siswa maka makin baik pula Hasil Lari Sprint 100 Meter. Sebaliknya makin rendah Koordinasi Mata Kaki makin rendah pula Hasil Lari Sprint 100 Meter. Terdapat hubungan antara Daya Ledak Otot Tungkai $\left(\mathrm{X}_{2}\right)$ dengan Hasil Lari 
Sprint 100 Meter (Y). Hal ini berarti makin baik Daya Ledak Otot Tungkai seseorang maka makin baik pula Hasil Lari Sprint 100 Meter. Sebaliknya makin rendah Daya Ledak Otot Tungkai makin rendah pula Hasil Lari Sprint 100 Meter. Terdapat hubungan antara Percaya Diri $\left(\mathrm{X}_{3}\right)$ dengan Hasil Lari Sprint 100 Meter (Y). Hal ini berarti makin baik Percaya Diri seseorang maka makin baik pula Hasil Lari Sprint 100 Meter. Sebaliknya makin rendah Percaya Diri makin rendah pula Hasil Lari Sprint 100 Meter. Terdapat hubungan secara bersama sama antara Koordinasi Mata Kaki $\left(\mathrm{X}_{1}\right)$ Daya Ledak Otot Tungkai $\left(\mathrm{X}_{2}\right)$ dan Percaya Diri $\left(\mathrm{X}_{3}\right)$ dengan Hasil Lari Sprint 100 Meter (Y). Hal ini berarti makin baik Koordinasi Mata Kaki, Daya Ledak Otot Tungkai dan Percaya Diri siswa maka makin baik pula Hasil Lari Sprint 100 Meter. Sebaliknya makin rendah Koordinasi Mata Kaki dan Daya Ledak Otot Tungkai makin rendah pula Hasil Lari Sprint 100 Meter.

\section{DAFTAR PUSTAKA}

Arikunto, Suharsini. 2013. Prosedur Penelitian Suatu Pendekatan Praktis. Jakarta: Rineka Cipta.

Britton W.Brewer, 2009. Sport Psychology. USA: Wiley Blackwell.

Faturahman Saleh. 2003, Hubungan Antara Motivasi Berprestasi dan Daya Ledak Otot Tungkai dengan Kemampuan Lompat Jauh di SLTP Negeri 103 Jakarta, Tesis, PPS UNJ.

Gerard Taylor, 2005. Capoera Conditioning. California: Blue Snake Books.

Ghufron Nur dan Rini Risnawati, 2010. Teori-teori Psikologi. Jogjakarta: Ar-Ruzz Media.

Hakim Thursan. 2005, Mengatasi Rasa Percaya Diri. Jakarta: Pustaka Juara.

Hendri Irawadi, 2011. Kondisi Fisik dan Pengukurannya. Padang : Fakultas Ilmu Keolahragaan Universitas Negeri Padang.

Husdarta, 2010, Psikologi Olahraga. Bandung: Alfa Beta.

IAAF, 2001, Pengenalan Kepada Teori Pelatihan Jakarta: Program 
Pendidikan dan Sistem Pelatih Atletik.

Johansyah Lubis, 2013, Panduan Praktis Penyusunan Program Latihan Jakarta: PT. Rajagrafindo Persada.

John Honeybourne, 2006, Acquiring Skill In Sport, New York; routledge.

Keith Davids, dkk, 2008, Dynamics of Skill Acquisition, USA; Human Kinetics.

Komarudin, 2013, Psikologi Olahraga. Bandung: PT Remaja Rosdakarya.

Laelatul Dewi Badriah, 2009, Fisiologi Olahraga. Bandung: Multazam.

Lee E. Brown, 2007, National Strength and Conditioning Association. USA, Human Kinetics.

Lumintuarso Ria, 2013. Teori Kepelatihan Olahraga. Jakarta: LANKOR.
Nicholas Ratamess, 2012. ACSM's Foundations of Strength Training and Conditioning. America: American College of Sports Medicine.

Mochamad Djumidar A. Widya, 2004, Belajar Berlatih Gerak-Gerak Dasar Ateitik Dalam Bermain, Jakarta : PT Raja Gragindo Persada.

Mylsidayu, Apta, 2014, Psikologi Olahraga. Jakarta: Bumi Aksara.

Mylsidayu, Apta dan Febi Kurniawan, 2015. Ilmu Kepelatihan Dasar, Bandung: Alfa Beta.

Raffly Henjilito, 2015, Pengaruh Daya Ledak Otot Tungkai, Kecepatan Reaksi, Dan Motivasi Terhadap Kecepatan Lari Jarak Pendek 100 Meter Pada Atlet PPLP Pekan Baru. tesis, PPs UNJ.

Syafrudin, 2011, Ilmu Kepelatihan Olahraga, Padang: UNP Press Padang. 
Sukadiyanto, 2011, Pengantar Teori Dan Metodologi Melatih Fisik, Bandung; Lubuk Agung.

Sukirno. 2012, Dasar-Dasar Atletik dan Latihan Fisik Palembang: Percetakan Universitas Sriwijaya.

Tangkudung, James, 2012. Kepelatihan Olahraga. Jakarta: Cerdas Jaya.

Tangkudung, James, 2006., Pembinaan Prestasi Olahraga, Jakarta: Cerdas Jaya.

Tangkudung, James, 2016, Macam macam Metodologi Penelitian, Lensa Media Pustaka Indonesia.
Tatang Iskandar. 2014, Hubungan Antara Daya Ledak Otot Tungkai, Kelentukan Punggung dan Motivasi Belajar Terhadap Keterampilan Lompat Tinggi Gaya Flop, Tesis, PPS UNJ.

Tudor O. Bompa dan G. Gregory Haff, Periodization Theory and Methodology Of Training

UU RI. 2005. Sistem Keolahragaan Nasional. Jakarta.

Widiastuti, 2015. Tes dan Pengukuran Olahraga. Jak 